\title{
RASTREANDO EL ORIGEN DE LAS ESTRUCTURAS DEL CONOCIMIENTO OCCIDENTAL FUNDADAS EN EL RACISMO EPISTÉMICO. HACIA UNA NUEVA PROPUESTA PARA LA DESCOLONIZACIÓN DEL PENSAMIENTO
}

\section{TRACING THE ORIGIN OF WESTERN KNOWLEDGE STRUCTURES BASED ON EPISTEMIC RACISM. TOWARDS A NEW PROPOSAL FOR THE DECOLONIZATION OF THOUGHT}

\author{
Elizabeth Gabriela Aguilar García \\ Doctorante en Ciencias en Salud Colectiva \\ Universidad Autónoma Metropolitana, UAM, México. \\ gabrielaaguilargarcia2@gmail.com
}

Recibido: 29 de enero de 2018 • Aceptado: 16 de febrero de 2018 Publicado: 28 de mayo de 2018

\begin{abstract}
Resumen
En los albores de la civilización occidental, la cultura griega, con la invención de la filosofía, y el pueblo hebreo, como pueblo elegido de Dios, se colocaron en la cúspide de la condición humana, uno de manera espiritual y el otro de manera filosófica racional; conformando así, la "tierra de abono" para el racismo y los genocidios/epistemicidios del siglo XVI, perpetrados por el cristianismo. Estos ingredientes teológicos, raciales e imperiales se manifestaron posteriormente en la filosofía moderna y han influido hasta nuestros días en el pensamiento occidental. Se propone a la meta epistemología de contextos como alternativa al colonialismo intelectual imperante en la academia latinoamericana recuperando el sumo respeto que le tienen a la naturaleza los pueblos originarios e incorporarlo en la construcción del conocimiento sin velado neoeurocentrismo, racismo epistémico e imperialismo.
\end{abstract}

Palabras clave: Racismo epistémico, colonialismo intelectual, epistemología, descolonización

Abstract

At the dawn of Western civilization, the Greeks, with the invention of philosophy, and the Hebrew people as God's chosen people, were place on the cusp of human condition. 
The first ones in a rational philosophical way and the second ones in a spiritual way. Shaping the "land of fertilizer" for the racism and the genocides/epistemicides of the sixteenth century perpetrated by Christianity. These theological, racial and imperial ingredients were manifested later in modern philosophy and influencing western thought to this day. It is proposed the meta epistemology of contexts as an alternative to the prevailing intellectual colonialism in the Latin American academy reincorporating the utmost respect that the indigenous peoples have for nature and linking it in the construction of knowledge no veiled neo eurocentrism, epistemic racism and imperialism.

Keywords: Racism epistemic, intellectual colonialism, epistemology, descolonization

No puede haber descolonización destruyendo a la madre tierra Silvia Rivera Cusicanqui

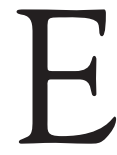
ste artículo parte de los planteamientos de Ramón Grosfoguel (2013) sobre los procesos históricos que produjeron estructuras de conocimiento fundadas en el racismo epistémico. De acuerdo con este autor, el privilegio epistémico de las teorías eurocentradas que se reproduce en las universidades occidentalizadas es el resultado de cuatro genocidios/ epistemicidios del largo siglo XVI: 1) contra la población musulmana y judía en la conquista de Al-Andalus, 2) contra los pueblos indígenas en la conquista del continente americano, 3) contra los africanos raptados y esclavizados en América, y 4) contra las mujeres quemadas vivas acusadas de brujas en Europa. Asimismo, este autor propone al ego extermino como mediación sociohistórica estructural entre el ego cogito de Descartes y el ego conquiro de Dussel (1994).

Reconociendo la importancia de su aporte al tema y su profundidad, agregamos otra dimensión que queda invisibilizada en los argumentos del autor y en la epistemología oficial de las universidades occidentalizadas: el origen civilizacional de dichas estructuras del conocimiento.

\section{Génesis de los cuatro genocidios/epistemicidios del siglo XVI: Su raíz civilizacional}

En este apartado, daremos paso a los planteamientos de Lara (2018, p.222), quien va más allá del siglo XVI rastreando los orígenes y la "tierra de abono" para estos cuatro genocidios/epistemicidios. Según este autor, es necesario buscar la raíz civilizacional de estos sucesos, que se ubica en el 
pensamiento griego y el monoteísmo judío - pilares de la civilización occidental-, y dejar de ponderar el largo siglo XVI como origen medular de este flagelo.

La eclosión de la intolerancia que condujo a los genocidios del siglo XVI encuentra sus raíces bajo la forma de un proto-racismo en el monoteísmo judío y en el pensamiento griego. Este proto-racismo se lo apropiará el cristianismo llevándolo a un racismo consumado (Lara, 2018). El cristianismo tiene sus orígenes en el judaísmo y el helenismo; sin embargo, ha renegado de su parte judía, pues "para la economía del cristianismo, el judaísmo debe desaparecer como actualidad, alojarse en el desván de la historia. El judío, vivo pero humillado, es necesario para demostrar la superioridad de lo cristiano" (Poliakov, citado en Sperling, 1991, p.82). En cuanto a su origen helénico, el cristianismo adopta de la filosofía griega sus contenidos metafísicos y los comienza a transmitir a través del monoteísmo, el cual es absorbido del judaísmo. El cristianismo es un sincretismo entre lo griego y lo judío, es una síntesis dialéctica (Sperling,1995, p.81).

Uno de los rasgos centrales del cristianismo es su mentalidad monocrática, la cual se desprende del monoteísmo y se opone a la pluralidad de ideas, así como al pensamiento crítico. Desde esta postura, abrirse a la diversidad, diferencias y negociación, habilidades necesarias para la convivencia social, resulta difícil. El cristianismo parte de la creencia de tener al Dios "único y verdadero" y su objetivo ha sido extender su dominio "como una bóveda universal, destinada a abarcar a todos los pueblos" (Burton, 2000, pp.113,139). El Dios cristiano no se asimila, exige lealtad exclusiva y obediencia estricta. Así, "fue el alcance universal de un Dios exclusivista lo que finalmente llevó a la intolerancia" (Burton, 2000, p.115). A partir de esta lealtad exclusiva al Dios cristiano, se legitima la violencia y la guerra "porque ese Dios quiere ser un Dios exclusivo, que no consiente a su lado ninguna otra cosa, "always at war with other gods" " (Dewick, 1953 citado en Deschner, 1986, p.57).

De acuerdo con la obra del historiador alemán Deschner (1986, p.181) Historia criminal del cristianismo, que consta de diez volúmenes, en la Biblia hebrea encontramos muestras de crímenes realizados orgullosamente en nombre de esa lealtad exclusiva. La idea de Dios que presenta dicha biblia es guerrera, en más de cien ocasiones, Yahveh ordena matar a personas, la violencia no sólo se justifica por violaciones de la ley sagrada, sino también 
por la arbitrariedad divina que pretende probar a los inocentes, como se muestra en el libro de Job o, simplemente, extermina sin motivo a quien quiere.

\section{Esdras y Nehemías: Proto-racismo en la Biblia hebrea}

El sacerdote Esdras es considerado como uno de los legisladores y reformadores judíos más importantes de los siglos V y IV, se destacó principalmente por declarar ilegítimos los matrimonios mixtos ordenando la expulsión de todas las mujeres extranjeras y sus hijos (Ídem). Cuando llegó a Jerusalén se horrorizó ante el hecho de que el pueblo no mantenía la sagrada separación de los goyim (Armstrong, 2008, pp.39-40).

"El pueblo de Israel, los sacerdotes y los levitas no se han separado de las gentes del país hundidas en sus abominaciones -cananeos, hititas, perizitas, jebuseos, ammonitas, moabitas, egipcios y amorreos. La raza santa se ha mezclado con las gentes del país, los jefes y los consejeros han sido los primeros en esta rebeldía” (Esdras cit. en Lara, 2018, p.191).

Fue tan radical que ni siquiera ofreció la posibilidad de que estas mujeres se convirtiesen a la religión judaica. Evidentemente, su motivación era más bien la de la pureza racial (Deschner, 1986:74). Cabe señalar que, aquel que se rehusara a la petición de Esdras sería expulsado de la comunidad y le serían confiscadas sus propiedades (Armstrong, 2008, p.151).

Por su parte, Nehemías continuó con la misión de Esdras rechazando a las mujeres extranjeras. Cuando Nehemías regresó de Babel a Jerusalén, no halló tarea más necesaria que la de combatir el liberalismo imperante, al que maldijo: "Los reprendí, y los excomulgué. E hice azotar algunos de ellos, y mesarles los cabellos, y que jurasen por Dios que no darían sus hijas a los hijos de los tales, ni tomarían de las hijas de ellos para sus hijos ni para sí mismos" (Nehemías 9:22 y 9:36, citado en Deschner, 1986, p.74). Todo ello en pro de la purificación de la raza y en defensa de la auto identificación como el "pueblo elegido", lo que justificaba la norma de segregación (Deschner, 1986).

En el judaísmo hay dos pasados: uno, que señala la Biblia con la alianza establecida ante Dios, este pasado pertenece a lo humano. El otro pasado está alejado para siempre de la naturaleza y pertenece a lo pre-humano. Retomando el pasaje de Sodoma y Gomorra, presencia ineludible en el 
imaginario judío, la estatua de sal se yergue separando lo que fue de lo que será (Sperling, 1995, p.111).

Ella, la mujer de Lot, está emparentada con Abraham y es, a la vez, su antítesis. Abraham marcha hacia adelante, parte y funda. A la salida de Sodoma y Gomorra -ciudades corruptas y sin ley- la mujer, sin nombre siquiera, añora, mira hacia atrás, se paraliza. Se reintegra - desea reintegrarse- a la naturaleza pero no es ya humana ni mineral. La vuelta atrás, dice la estatua, es imposible. La estatua de sal dice, entonces, que hay dos pasados: uno que debe ser constantemente recreado, y el otro al que no se debe -no se puede- retornar. El primero pertenece a lo humano; el segundo, perdido para siempre, a lo pre-humano.

En la lógica del monoteísmo, tenemos por un lado, lo que debe perderse para siempre y hundirse en la noche de los tiempos, aquel magma primordial, del cual el hombre se ha separado y diferenciado. Por otro lado, está el otro origen, la otra memoria que guarda los sucesos fundantes. Lo que se recuerda y se recrea no es el origen natural sino el histórico (Sperling, 1995, p.111). En el judaísmo, lo "natural sólo adquiere sentido cuando es resignificado por una historia que es antropocéntrica" (Lara, 2018, p.208).

De acuerdo con Lara (2018, pp.221-222), la línea divisoria presente en el monoteísmo judío que separa al pueblo elegido de los pueblos no elegidos conformó la "tierra de abono" para el racismo que emergió en el siglo XVI, implementado por el cristianismo que distinguía a los humanos de los no humanos. Insertos en la lógica de una línea divisoria de la humanidad -configurada como proto-racial- quedaron, por un lado, el pueblo elegido, en alianza exclusiva con Dios, y por otro, el pueblo griego, con la categoría filosófica del Ser, ambos en la cúspide de la condición humana, uno de manera espiritual y el otro de manera filosófica racional.

\section{El pensamiento griego: Androcéntrico, excluyente y proto-racial}

El varón libre de Atenas es "lo mismo", el que domina a la especie y a la mujer, la mujer es "el otro" subordinada y dominada. El niño también es devaluado, quedando en calidad de sub hombre. Los bárbaros tampoco eran considerados plenamente hombres, pues para Aristóteles los bárbaros son 
fuertes; pero no son hábiles ni inteligentes. Y, finalmente, los esclavos, son simples cosas a disposición de, instrumentos con alma. Así, tenemos que, el varón se encuentra en una condición de superioridad ante la mujer, los niños, los bárbaros y los esclavos. Únicamente los griegos de la Polis tienen la totalidad humana. Son los áristoi, es una antropología esencialmente aristocrática y una dominación naturalmente justificada (Dussel,1980, 263-264).

Por otro lado, Platón ha sido considerado como el padre del pensamiento occidental (De Bono, 1995, p.23). La supremacía de los griegos sobre los bárbaros era un punto que destacaba en su pensamiento, él entendía la relación entre éstos dos desde la perspectiva del Pólemos, lo cual significaba que el conflicto era imperecedero y radical. En su obra, Las Leyes, hace un reconocimiento a espartanos y atenienses por haber resistido al bárbaro invasor ponderando la pureza racial:

Gracias a semejante heroísmo, los griegos, a diferencia de tantos otros pueblos vecinos, no eran una nación mezclada, un coctel racial. Donde gobiernan los persas la población es una mezcla: no hay distinciones, tipos puros (Carballo, 2012, p.107).

Dada la influencia de Platón en el pensamiento occidental, no es extraño que éste haya sido de "una naturaleza intrínsecamente fascista, con reglas rígidas, juicios severos, inclusión y exclusión, casillas y juicios categóricos y un alto grado de rectitud. Platón era un fascista redomado" (De Bono, 1995, p. 23). Borges (citado en Serna, 2011, p.172) ha señalado que en La Republica se encuentran los gérmenes de Nazismo. Por su parte, Serna (2011) afirma que en la Idea de Platón se prefigura el pensamiento único:

Apostar por un pensar descontextualizado, emancipado de la temporalidad, ávido de eternidad, como en su momento haría Platón, si bien constituye la condición de posibilidad de la ciencia natural, prefigura, no obstante, el pensamiento único [negritas añadidas]. (Serna, 2011, p.172)

En el pensamiento griego observamos un tácito proto-racismo y un monopensamiento donde no hay cabida para algo más, estos ingredientes fueron exacerbados por el cristianismo en el siglo XVI (Lara, 2018, p.219). 
Ahora bien, tanto los griegos como los judíos, dieron inicio a la separación metafísica de la realidad, hecho sin precedente en la historia de la humanidad. Los griegos lo hicieron de manera racional, a través de la Filosofía y la ciencia, y el pueblo judío de forma espiritual, vía el monoteísmo (Lara, 2018, p. 227). A continuación veremos, grosso modo, cómo se fueron dando estos procesos.

\section{Separación metafísica de la realidad llevada a cabo por los griegos en los albores de la civilización occidental}

Con el colapso del Mediterráneo (siglos XII al VIII a.c), los griegos se fueron alejando de sabidurías ancestrales, tales como la egipcia y la babilónica. Devaluando el vínculo que éstas tenían con la naturaleza y el cosmos, inventaron una mitología, que si bien guardaba resquicios de cosmogonías anteriores, se fue tornando antropomorfa y androcéntrica, lo cual, fue uno de los factores que propiciaron, de manera gradual, la separación metafísica de la realidad (Lara, 2018, p.230). Por otro lado, con el salto del mito al Logos, el griego continúa la tendencia de dar la espalda a la naturaleza al inaugurar un pensamiento desprendido de la Physis. Posteriormente, cuando se asume como Ser racional, se separa de los animales, las mujeres, los niños y los bárbaros por considerarles jerárquicamente inferiores; marcando con esto, nuevamente una separación ontológica con la realidad. Finalmente, la emergencia de las lenguas indoeuropeas más la adopción de la escritura alfabética que tomaron de los fenicios, facilitaron la escisión entre la realidad concreta y la realidad abstracta, dado que dichas lenguas y escritura son lineales, predicativas y abstractas. Por ejemplo, la abstracción de los verbos en infinitivo es tal que parecen actuar por sí mismos al prescindir del sujeto y del contexto, a diferencia de otras lenguas como el náhuatl y el aymara que no admiten verbos vacíos de referencias. Considerando todo lo anterior, no es casualidad que Aristóteles y Platón, los pensadores griegos más importantes de esa época, no tuvieran observatorio astronómico (Lara 2018).

En este proceso de separación metafísica de la realidad, los griegos van a necesitar con urgencia sujetarse de algo para no flotar como huérfanos en el vacío y van a inventar conceptos que, hipostasiados y deificados, les servirán de soporte a su existencia. Esto dará paso a la fragmentación conceptual de 
la realidad, la cual comenzó en el periodo presocrático de la filosofía griega cuando se intenta explicar el universo a partir de un solo principio, arjé, y se obliga a gravitar todo alrededor de estos conceptos (Lara, 2018).

Posterior a la etapa presocrática, viene Platón con la Idea y será aquello que posea mayor grado de consistencia ontológica (Sperling, 1995, p.38). Aristóteles, por su parte, dará inicio a la división del saber en distintas disciplinas, producto de esta inercia de fragmentar conceptualmente la realidad, lo cual dominará más tarde en el paradigma de la ciencia clásica, cuyo principio de explicación se basa en la disyunción y en la reducción del conocimiento. Cuatro siglos después del auge de la filosofía griega, surge Jesucristo como un concepto deificado que es el Logos, la Razón ilustrada fue otro concepto deificado que después se secularizó. Otros vocablos que se deificaron fueron la voluntad con Schopehauer y Nietzsche, la recuperación del Ser con Heidegger, la existencia con Sartre, el mercado, concepto hipostasiado por el neoliberalismo, etc. (Lara, 2018).

\section{La ontología se inventa para tapar el "horroroso vacío" con una presencia de carácter conceptual}

La filosofía occidental se fue configurando como un pensamiento desprendido de la Physis, planteando exigencias de orden y de aprehensión de lo existente, basando su desarrollo en el Ser como categoría central (Sperling, 1995, p.56). Justo después de la guerra del Peloponeso, aparecen las obras de Platón y Aristóteles y se empieza a ver a la filosofía como una posible cura al mal que aquejaba al tejido social en ese momento. Es Platón quien establece esta relación entre medicina y filosofía, la cual estaría destinada entonces a reparar una comunidad enferma (Sperling, 1995, p.83).

Algo se ha perdido y urge recuperarlo, la falta abre un vacío que amenaza con tragarlo todo. Es preciso para el griego que algo extremadamente firme, sólido e incuestionable, ocupe ese lugar a fin de evitar el derrumbe de un mundo y la disolución de una cultura.

De acuerdo con Sperling (1995, p.84), este fue el punto de partida que dio origen al fundamento de una realidad que parecía no estar del todo firme. 
Los filósofos griegos se enfrentaban a la tarea de "atar la vida, de afirmarla" a través de la palabra y la explicación. El Menón es un esfuerzo por fijar el saber, se empieza a invocar a una presencia constante que fije el sentido de la vida y garantice su permanencia. Es aquí donde se vislumbra el nacimiento de la Ontología, cegando con su resplandor y apariencia de firmeza al pensamiento griego.

La Ontología coloca al Ser y a sí misma como el fundamento de todo pensar. El eje Ser/no Ser se va a constituir en un proto paradigma, pues todo pensar, todo mirar, todo afirmar, todo disentir y todo negar quedan pre y sobre determinados por este vocablo (Sperling, 1995, p.84). Así, la categoría omnívora del Ser pasará a vertebrar el discurso oficial de occidente (Sperling, 1995, p.128).

Desde el instante en que el Ser se establece como fundamento, la palabra no puede tener otro destino que intentar decir el Ser aprehender lo absoluto, arañar lo Real (Sperling, 1995, p.56)

Bien lo señaló Aristóteles, el Ser se dice de muchas maneras, pues se configura como Logos también (Sperling, 1995, p.56). Así, tenemos que el Logos está atravesado por esa Ontología que coloca al Ser como el fundamento de todo pensar:

El Logos se gesta a la sombra del Ser y tiene como referente a la Idea, en tanto es ésta la encarnación de lo que es en sí. La Idea, a su vez, desplegada en el Logos, devendrá concepto, derivación lógica de un principio Ontológico (Sperling, 1995, p.57)

La ontología se inventa entonces para tapar el vacío existencial del griego orillándolo a sujetarse, con desesperación, de sus conceptos -tales como Ser, Número (con Parménides), Eidos o Idea-, creando un universo separado sin más referente que él mismo (Lara, 2018).

\section{La separación espiritual de la realidad llevada a cabo por el pueblo judío}

Por el lado del judaísmo, la separación de la realidad se llevó a cabo de manera espiritual a través del monoteísmo y de la Biblia, erigiéndose 
como el pueblo elegido y como el plus de toda la creación por su alianza exclusiva ante Dios, “el Dios único y verdadero”. La religión de Moisés dará consistencia a ésta superioridad del Dios de Israel sobre los demás dioses (Deuteronomio 6:4; Éxodo 20:3, citados en Lara, 2018, p.263).

Con la particularidad del monoteísmo israelita que se funda en una alianza androcéntrica y exclusiva ante Dios y no en una relación con la naturaleza o el cosmos, al colocarse el pueblo hebreo en la cúspide de la creación, queda por encima de las plantas, de los animales, de las montañas, de la tierra y los planetas. Esta separación entre el "mundo natural" y el "mundo divino" fue un parteaguas en la historia, ya que, el humano se coloca por encima de todas las "criaturas", dado que fue creado a imagen y semejanza de Dios, idea monoteísta que después la retomará el cristianismo (Lara, 2017:265).

Una consecuencia del monoteísmo es la idea de que Dios, como señor del universo y de la historia, la entera realidad no es una prolongación de la realidad divina sino que es positivamente distinta de Dios y a él está subordinada en una suerte de autonomía relativa" (Garzanti, 1992, citado en Lara, 2018, p.266)

Con esta desacralización de la naturaleza, el pueblo judío inicia la separación de la realidad, a partir de un Dios mono conceptual, abstracto y genérico que succiona para sí toda la sacralidad del universo, apropiándose de todo el respeto sumo que se le tenía a la naturaleza. La noción de un Dios abstracto y alejado del cosmos la tomaron los judíos del henoteísmo solar de Amenofis IV (décimo faraón de la dinastía XVIII de Egipto), quien cambió su nombre por Akhenatón (1370-1350 a.C.) y fundó la ciudad de Amarna para este nuevo culto al Sol (Lara, 2018, p.269).

El henoteísmo revolucionó la cosmovisión egipcia y abrió paso al monoteísmo judío. En el Henoteísmo se privilegia a un Dios único, sin negar a otros dioses. El henoteísmo es una fase de transición entre el politeísmo y el monoteísmo, que se apega a la taxonomía monoconceptual y escindidora de la realidad de la civilización occidental (Lara, 2018, p.269). 


\section{Los cuatro magno paradigmas de la civilización occidental y los cinco dogmas del eurocentrismo}

Ahora bien, la separación metafísica de la realidad, la fragmentación conceptual de la realidad, la desacralización de la naturaleza, y el antropocentrismo son los cuatro magno paradigmas que gobiernan el pensamiento del hombre occidental y del colonizado, teniendo además, implicaciones epistemológicas que han conducido a un racismo epistémico en las ciencias sociales y en la filosofía (Lara, 2018, p. 272). Asimismo, hay cinco dogmas del eurocentrismo que aluden a la "universalidad" y permean el pensamiento occidental, tales dogmas son): 1) la filosofía es universal, 2) la realidad definida por los europeos es universal, 3) la razón es universal. Para ser considerados seres humanos, los otros pueblos del mundo tienen que llegar a ser "racionales", 4) las ciencias sociales son universales, 5) las categorías dominantes de la civilización occidental son "universales" (Lara, 2018, p.280). Ahora veamos cómo se han expresado estos paradigmas y dogmas en la filosofía moderna.

\section{Del proto-racismo en la filosofía griega al racismo tácito en la filosofía moderna}

El hombre moderno no sólo niega al Dios del medioevo sino que se instituye él mismo como totalidad. El Ser va a ser "lo constituido desde por y en el ego, de tal manera que ya no es una totalidad física sino una totalidad egótica, un sujeto" (Dussel, 1980, p.265). El ego cogito será el comienzo del Ich denke de Kant y del Ich arbeite de Marx, que aunque distantes en el tiempo, son en realidad "lo mismo" (Dussel, 1980). Lara propone el Ich kaufe (yo compro) del capitalismo para terminar de completar este cuadro. Tenemos así que, el Ich denke (yo pienso), el Ich arbeite (yo trabajo) y el Ich kaufe (yo compro) se desprenden del Yo Imperial, el cual adquirió su condición de posibilidad en el ego extermino y el ego conquiro señalados por Grosfoguel (2013) y Dussel (1994). En una mirada de conjunto, observamos aquí diversas expresiones de un mismo antropoteísmo secularizado, inscrito en un continuum civilizacional que viene a ser teológico, racial, genocida, intolerante e imperial (Lara, 2018, p.311). 


\section{La razón imperial}

En la historia del pensamiento occidental, Hegel representa un destino: la culminación de la tradición filosófica (Fernández, 2000). Con este filósofo se alcanza la plenitud de la totalización moderna "El Ser es el saber y la totalidad es el absoluto" (Dussel, 1980, p.265). Para Hegel la razón "es negativa y dialéctica, porque resuelve en la nada las determinaciones del intelecto; es positiva, porque crea lo universal, y en él comprende lo particular" (Hegel, 1976, p.29). El punto más alto del logos culmina en la dialéctica hegeliana "donde la diferencia deviene negatividad para posibilitar el triunfo final de lo idéntico en la síntesis, que devora toda otredad. Síntesis y espíritu absoluto, logos que todo lo absorbe, razón que deglute al mundo" (Sperling, 1995, p.101).

Con la frase "todo lo que es real es racional y todo lo que es racional es real” Hegel supone que a la realidad le es consustancial la razón ¿Que ha ocurrido aquí? Que no sólo las antiguas trascendencias reservadas a Dios son trasmitidas al hombre, transfiguradas en ontología (Robles y Arnold 2001, p.75), sino que, además, la razón misma es sacralizada y deificada por el europeo del siglo XVIII tornándola universal. Así, en una acción imperial sin precedentes, la razón deglute no sólo a la realidad sino a todas las culturas del mundo (Lara, 2018, p.319). El logos es un decir esencialmente imperialista (Sperling,1995, p.57). Simulando el sacramento de la Eucaristía, Hegel efectuó la transustanciación de la razón a la realidad, dándose esto en el acto mismo de conocer. Dicho sacramento consiste en consagrar el pan en el cuerpo de Cristo y el vino en su sangre. Esta acción no es meramente simbólica sino real, ya que a través de la fe, Jesús está real y personalmente en la hostia y en el vino que el sacerdote consagra. A esto le llaman los cristianos, el misterio de la transustanciación (Lara, 2018, p.323).

El hombre en la modernidad es Imago Dei y la razón, al quedar divinizada, pasa en transustanciación secularizada a las teorías científicas para después, en un acto teológico imperial, proceder a su "universalización evangélica" (Lara, 2018, p.323). La universalización del conocimiento tiene entonces un trasfondo teológico, no sólo porque es equivalente a la universalización del Dios cristiano, como ya lo ha señalado Grosfoguel (2013, p.36), sino también porque ese conocimiento contiene "la sustancia divina 
de la razón" que absorbe características trascendentales de Dios como la omnisciencia y la omnipresencia (Lara, 2018, p. 326). De acuerdo con Dussel (1980, p.265), lo más grave del hombre moderno no fue negar al Dios del medioevo sino que él mismo se instituyó como totalidad. A esto, agregamos que, aún más grave ha sido caer en la ilusión colonialista de creer que la razón es "universal" cuando sólo se trata de la herramienta de conocimiento propia de la civilización occidental. Para que la razón sea universal tendría que ser autónoma, es decir, tendría que fundamentarse en sí misma, no estar condicionada histórica, social ni culturalmente. Tendría que poseer una pureza ontológica (Lara, 2018, p. 328). Este ideal de la autonomía de la razón se gestó en la Ilustración, cuando se secularizó el cristianismo y constituye su esencia misma. La Ilustración representa la conquista histórica del Logos heleno cristiano (Reyes, 1998, p.209-210).

Tenemos así que, "el hombre occidental y su herramienta de conocimiento -la razón- se deifican, y en su unión sagrada, se vuelven intangibles, transhistóricos, meta-culturales y por tanto, universales. Actuando desde un no-lugar y mirando desde el ojo de Dios, el europeo, en autosuficiencia ontológica, lanza la Biblia a un lado y se yergue altivo, sosteniéndose ahora con el báculo sacrosanto de la razón en el siglo de las luces” (Lara, 2018, p. 331). En esa euforia teológica y orgullo imperial racional, la pars se confunde con el totum. Se invisibiliza el provincianismo, y queda oculta la teología e imperialismo que son consustanciales a la Razón occidental (Lara, 2018, p. 331).

Ahora bien, en la epistemología occidental, se da por sentado que la razón es consustancial a la realidad, incluso en las llamadas "epistemologías del sur" que afirman partir de un Logos emancipador:

Esta otra epistemología que tiene su génesis en la Teoría Crítica y se recrea en América Latina, desde el Sur, se asume desde la praxis de un logos emancipador que fractura los límites hegemónicos del capitalismo sin fin y del colonialismo sin fin (De Sousa, 2011, p.17)

Si el objetivo de las epistemologías del sur es lograr la descolonización del conocimiento, debemos empezar por la descolonización del pensamiento, en su trasfondo civilizacional, para poder dar cuenta de las cegueras paradigmáticas que gobiernan a la academia; sólo así podemos detectar que el 
Logos es una categoría heleno cristiana secularizada y que en la frase "logos emancipador" hay una irradiación teológica e imperial con bandera emancipadora que pone de manifiesto un neocolonialismo oculto.

Haciendo eco de las palabras de Sperling (1995) tenemos que "si el logos permite el despliegue de lo múltiple y lo diferente, es sólo para subsumirlo, para reapropiárselo, para regirlo, para colonizar el caos que le aterra" (p.100). Así, El logos es una postura occidentalocéntrica ante la realidad que obedece fielmente a los cuatro magno paradigmas antes mencionados: se separa ontológicamente de la naturaleza, la desacraliza, fragmenta conceptualmente la realidad y es antropocéntrico. No podemos hablar de una verdadera emancipación si seguimos adoptando las categorías imperialistas de occidente, su manera de percibir la realidad y de construir el conocimiento.

Considerando lo anterior, la concepción de "epistemologías del sur" debe ser revisada a la luz de los cuatro magno paradigmas de la civilización occidental. Si nos remitimos a la definición dada por de Sousa Santos (2011) podemos percibir que tiene dos acepciones:

Entiendo por epistemología del Sur el reclamo de nuevos procesos de producción y de valoración de conocimientos válidos, científicos y no científicos, y de nuevas relaciones entre diferentes tipos de conocimiento, a partir de las prácticas de las clases y grupos sociales que han sufrido de manera sistemática las injustas desigualdades y las discriminaciones causadas por el capitalismo y por el colonialismo (p.35)

Por un lado, se refiere a una corriente académica racional que tiene por objetivo la descolonización del conocimiento y la igualdad entre diferentes tipos de saberes. Por otra parte, dentro de esta misma corriente, el término de "epistemologías del sur" se usa igualmente para denominar a aquellos otros conocimientos de grupos oprimidos, como podrían ser, los pueblos indígenas que no han sido reconocidos o validados por la academia oficial. El problema con esta última acepción, es que se presupone que la epistemología -conocimiento racional occidentalocéntrico- es universal. Es decir, que los saberes de los pueblos indígenas fueron construidos con base en esta herramienta de conocimiento propia de occidente, lo cual es falso, ya que una de las característica de la epistemología occidental es que no admite el 
respeto sumo al universo, puesto que, marca una escisión ontológica entre el hombre y lo divino desplazando el conocimiento al terreno de lo laico, y en esta secularización rompe el vínculo sagrado ${ }^{1}$ con la naturaleza. Así, en el proceso de construcción del conocimiento, la epistemología se separa ontológicamente de la naturaleza. Esto es porque obedece a los cuatro magno paradigmas arriba mencionados, a diferencia de los saberes y sabidurías de las cosmogonías indígenas que nunca se separaron ontológicamente de la naturaleza ni la desacralizaron. Los pueblos originarios no necesitaron separarse de la realidad para dar cuenta de ella. Sus saberes y conocimientos son concebidos como sagrados por estar vinculados y en armonía al cosmos, del cual se sienten parte indisoluble. En este sentido denominar "epistemologías del sur" a los saberes de los indígenas es obedecer al quinto dogma del eurocentrismo sobre las categorías dominantes, pues el concepto occidental de "epistemología" se universaliza europeizando las sabidurías indígenas y asumiendo que sus conocimientos son racionales. Con ello se da por hecho que la razón es universal, lo cual es en realidad otro dogma eurocéntrico.

\section{La filosofía como instrumento de dominación colonialista}

Krishna (1986, p.59) se ha dado a la tarea de reflexionar sobre el tema de la filosofía comparada desde una postura crítica, enfatizando las dificultades que implican los estudios comparativos en este campo, y formulándose preguntas como las siguientes ¿Cómo se podría admitir la posibilidad de la existencia de una filosofía fuera de la tradición occidental si lo que se hace es compararla o estudiarla justamente desde el esquema y la estructura conceptual de la filosofía de occidente? ¿Cómo saber si estamos hablando de lo mismo o de cosas diferentes?

Cualquier intento de filosofar comparativamente conduce de manera inevitable a la conciencia de que existe una estructura conceptual alternativa, una forma distinta de ver el mundo, una forma distinta de delinear el terreno cognoscitivo diferente a aquella a la que uno está habituado. Y sin embargo por más natural que pudiera parecer esta expectativa, no fue esto lo que sucedió (Krishna, 1986, p.59)

1 Más adelante se expone la definición de "sagrado" propuesta por Lara (2018). 
No sólo son comparaciones entre distintas filosofías sino también son comparaciones entre distintas sociedades, culturas, y civilizaciones, puesto que se hace un intento de observar otra realidad, desde el punto de vista de aquella que no es la misma (Krishna, 1986, p. 57-58). Ninguna cultura o tradición puede adjudicarse un sitio privilegiado dentro de este juego de observar otra cultura, ni puede comprenderla, juzgarla y evaluarla en función de sus propias reglas. Sin embargo, se ha tratado de encubrir la contradicción subyacente al fundamento mismo de los estudios comparativos recurriendo al universalismo que occidente deposita en sus conocimientos (Krishna, 1986, p.64).

Y como consecuencia de esta irradiación del universalismo imperial de occidente, los sabios de sociedades y culturas no occidentales, en vez de observar desde su propia perspectiva a las sociedades y culturaras occidentales, aceptaron las normas de los eruditos de occidente tratando de demostrar sus avances en varios campos, tal fue el caso de los sabios de la India que "se tragaron el anzuelo, el sedal y la plomada" preocupándose por demostrar que la "filosofía hindú" -interesada principalmente en el concepto de moksa (la liberación del sufrimiento) - contaba con una sofisticación epistemológica y ontológica a la altura de la filosofía europea, aun cuando la filosofía hindú no se impartiera en la mayoría de las universidades occidentales. Esto es un claro ejemplo de la imposición tácita de que los modelos occidentales son universales (Krishna, 1986, pp. 60,62).

\section{La categoría omnívora del Ser}

Una de las categorías centrales de la filosofía es el Ser. Es una forma de entender la realidad, desde la cual, todo el pensamiento queda estructurado sobre la base de este eje, y como categoría omnívora que es, ha vertebrado el discurso oficial de occidente (Sperling, 1995, p.94). Si bien el reinado del ser no ha transcurrido sin altibajos -teniendo oposiciones, reformulaciones y cuestionamientos- la historia metafísica de occidente ha girado en torno a "la dominancia de una forma gramatical: la tercera persona singular presente del verbo ser: es” (Heidegger citado en Sperling, 1995, p.94). Dada la relevancia del verbo Ser como categoría filosófica, ¿cómo podemos decir que la filosofía es universal, si en muchas lenguas no existe tal verbo? 


\section{El verbo Ser: Característica propia de las lenguas indoeuropeas}

En hebreo no se conjuga el verbo Ser en presente, "no hay es, no hay soy. No hay verbo Ser en presente ni con sentido existencial ni con sentido de cópula. Ehie asher ehie, no significa 'soy el que soy' como desde siempre la tradición -traducción/traición- cristiana lo ha consignado", dado que Ehie, en realidad no representa al verbo soy (Sperling 1995, p.94). Ehie no puede, en modo alguno, significar soy "por la mera imposibilidad lingüística de articular tal forma verbal, tampoco expresa ni siquiera aproximadamente ningún matíz del Ser, ni de la hiperesencialidad ni de nada que se encuadre en una comprensión ontológica" (Sperling, 1995, p.95).

Si nos apegamos al verdadero significado de la frase Ehie asher ehie, tenemos que ésta representa "la grandeza de Aquel que no se puede aprehender en el Ser como presente ni como esencia ni como nombre ni como ente, aún ente supremo o ente por excelencia” (Sperling, 1995, p.95). En suma, tenemos que esta frase hebrea es intraducible a las lenguas occidentales, dado que la traducción le imprime necesariamente el sello del verbo Ser, conduciéndola "a un equívoco insalvable: el que se deriva del sentido ontológico que tal verbo instala de inmediato en la frase, con toda la carga de sentido y la centralidad que tal sentido conlleva" (Sperling, 1995, p.96).

En aymara tampoco existe el verbo Ser. La morfosintaxis aymara obliga a "ser eso" o "ser aquello" o "ser alguna cosa" pero no admite un verbo Ser vacío de referencias. Esto significa que es imposible decir que simplemente "se es". En aymara la función copulativa no la cumple ningún verbo (modo europeo). Se implementa mediante sufijos. La función copulativa se encuentra dispersa y no concentrada, por tanto, buscarla en un solo sufijo o en un conjunto reducido de ellos es inútil (aymara.org, 2010).

El verbo Ser es una de esas características que son únicas a las lenguas indoeuropeas. Muchas lenguas no poseen nada que sea análogo, incluidas las lenguas jaqi (Taylor y Hardman, 2004). De acuerdo con Jesús Lara (2018, p.119), el intentar extrapolar el vocablo Ser a otras lenguas no indoeuropeas representa una forma de racismo lingüístico, que en su especificidad, sería un racismo ontológico, ya que, se magnifica el vocablo Ser por encima de todas las demás lenguas del mundo concibiéndolas como inferiores. 


\section{La desjudaización de la filosofía como punto ciego de la civilización occidental}

La civilización occidental se ha sostenido en dos columnas milenarias: el pensamiento griego y el monoteísmo judío (Lara, 2018, p.52). Sin embargo, el europeo, por un lado, fue negando una de estas columnas al desjudaizar la teología, la ciencia y la filosofía, y por otro, fue ponderando el heleno-cristianismo estacionándose en éste pilar. Soslayado, el judaísmo se convirtió en el punto ciego de occidente (Sperling, 1995, p.25). Grecia y Judea fue la intersección donde comenzó la ceguera y se oficializó la práctica del ocultamiento (Sperling, 1995, p.51).

El judaísmo recorre la historia de occidente desde un lugar atípico y atópico, un lugar que es un no-lugar, un exilio totalizador, marca sus orígenes, pero esa marca es incesantemente borrada" (Sperling, 1995, p.26). Dado que la religión dominante en occidente es el cristianismo, el judaísmo ha permanecido oculto o leído desde el cristianismo y esta es la lectura que la filosofía hereda aun en su versión laica (Sperling, 1995, p.21).

Hegel fue quizá el filósofo al que más le preocupó el judaísmo. Sus interpretaciones sobre este tema las manifestó en sus obras La fenomenología del espíritu y las Lecciones sobre la filosofía de la historia. En la primera obra, el judaísmo representa para Hegel el prototipo de la conciencia desdichada donde todo lo que se genera es antítesis en lugar de la síntesis reconciliadora (Küng, citado en Herrero, 2015, p.58). El judaísmo, sería la fase de la conciencia desdichada en la que más desgarradamente se vive la relación contrapuesta entre lo inmutable, Dios, y la simple nulidad que ante él representa todo lo mutable. En cambio, en el cristianismo, la particularidad transita hacia lo inmutable, en tanto lo divino se ha hecho patente en el Hijo del hombre. Es el estadio en el que lo inmutable entra en la conciencia al mismo tiempo que es tocado por lo singular. Es el movimiento en el que la conciencia empieza a experimentar el surgir de lo singular en lo inmutable y de lo inmutable en lo singular. La tercera fase, en la que lo inmutable se invierte en la particularidad de la conciencia misma, expresaría la culminación del cristianismo en el ateísmo de la Aufklärung (Herrero, 2015, pp. 64,65). 
Posteriormente, en las Lecciones sobre la filosofía de la historia, la interpretación de Hegel sobre el judaísmo da un viraje donde aparentemente lo reconoce como una manifestación del saber de sí del espíritu. Sin embargo, esta reconsideración no se basa en el valor intrínseco del judaísmo y su relación con el saber, sino que es reconsiderado sólo porque representa un estadio del absoluto hacia sí mismo (Herrero, 2015, pp.64, 65).

La reconsideración a la que Hegel somete su interpretación no podría interpretarse bajo ningún concepto como una revisión sensu stricto de su posición inicial frente al mismo sino, más bien, como una reducción de la religión judía a paso necesario de esa gran Teodicea para la justificación del absoluto que es la Historia universal (Herrero, 2015, p.64).

La acusación contra los judíos que comparten Hegel, Kant, Heidegger, y Nietzsche, y se enfoca en que son un pueblo sin suelo, sin propiedad, nómada y desraizado, lo cual, desde esta lógica heleno prusiana los convierte ante los ojos de Heidegger en seres sin Ser, mientras los griegos habitaban en el Ser, los judíos sobreviven en la Nada. "En un contexto en el que los alemanes arios se reclaman herederos culturales de los antiguos griegos, la judaización de la cultura alemana significaría introducir el virus de la Nada en el corazón de la esperanza de un renacimiento del Ser" (Navajas, 2015).

\section{La filosofía occidental no tiene los recursos meta-epistemológicos para observarse y criticarse a sí misma}

La filosofía, sensu stricto, es occidentalocéntrica, no puede hablar en nombre de toda la humanidad, sin embargo presupone ser la única y excelsa manera de reflexionar en el mundo, aun cuando existe una vasta diversidad de discursos y saberes en el planeta. Sus cegueras paradigmáticas y ansias evangélicas de universalidad le impiden salirse de su provincianismo epistémico, por lo que requiere de una mirada de conjunto que la desmitifique y la ubique en el contexto civilizacional al que pertenece (Lara, 2018, p.402). Para lograr lo anterior, se propone un desbordamiento epistemológico que permita la apertura a distintos saberes, que en igualdad y respeto, participen en la creación de una nueva civilización. Otra epistemología y civilización 
que reincorporen el sumo respeto que le tienen al cosmos y a la naturaleza los pueblos originarios. Esta nueva propuesta llamada "meta-epistemología de contextos" tiene como ejes centrales el diálogo fraterno con otros saberes más allá de lo instituido -sin velado neo-eurocentrismo, racismo epistémico e imperialismo- y el respeto sagrado a la vida entretejido con la construcción del conocimiento. Cuando hace referencia a lo sagrado, este autor no alude a la concepción religiosa, monoteísta, antropocéntrica ni metafísica de occidente, sino que se refiere al respeto sumo a la vida, es decir, a la naturaleza de la cual somos parte indisoluble, y que "por su gratuidad, belleza y valor máximo adquiere el carácter de sagrado" (Lara, 2018, p.405).

Los tres niveles operativos de esta propuesta son: 1) el intra-occidental, el extra-occidental y el inter-civilizacional. El nivel intra-occidental. Se refiere al ámbito endógeno de occidente que no detecta ni trasciende sus paradigmas que lo estructuran: a) separación metafísica de la realidad, b) desacralización de la naturaleza, c) fragmentación conceptual de la realidad y d) antropocentrismo. Además de los cinco dogmas centrales del eurocentrismo ya señalados. En este ámbito predomina un pensamiento contra natura, androcéntrico, racial e imperial (Lara, 2018, 405).

El nivel extra-occidental. En este nivel, primeramente, debemos hacer una precisión, cuando nos referimos al término extra occidental, no lo hacemos de un modo ontológico, como si hubiera una realidad aparte, ya que no hay una exterioridad absoluta a occidente, ni a la inversa: una influencia absoluta de occidente en otras culturas. Solamente lo utilizamos en un sentido operativo, como apertura a otros saberes no occidentales. Ahora bien, Lara (2018, p.411) señala, que el tener una mirada extra occidental le fue posible gracias a su condición de mestizo ${ }^{2}$, la cual permite ser sujeto y objeto en la observación tanto de la cultura indígena como de la europea, condición a la que la autora de este artículo también se suscribe. La situación bi-civilizacional que nos estructura como sujetos epistémicos mestizos nos da un ángulo de exterioridad y, a la vez, de interioridad respecto a la tradición occidental, ángulo del que carecen el europeo y el criollo. Asimismo, dicha situación posibilita una mirada más amplia y alterna que

2 La condición de mestizo, per se, no genera automáticamente esta perspectiva extra occidental, pero sí puede contribuir, de manera potencial, a enriquecer la búsqueda y los esfuerzos de los sujetos por la descolonización del pensamiento. 
enriquece los esfuerzos para la descolonización del pensamiento, asumiendo en igualdad y respeto las dos civilizaciones que nos conforman, sin negar o ponderar una respecto de la otra. De aquí la importancia de develar las diferentes identidades de los sujetos epistémicos que construyen el conocimiento y que comúnmente quedan invisibilizadas en la academia: criollos, mestizos, indígenas, europeos, afroamericanos, etc. Cabe resaltar que, no entendemos estas identidades como esencialistas o cerradas en sí mismas sino como dinámicas, flexibles, provisionales y ajustables a las experiencias de los sujetos (Lara, 2018, p.411).

El nivel inter-civilizacional. Este plano abre el espectro de la epistemología occidental a la emergencia de una meta epistemología de contextos donde el contexto se amplifica a un nivel de mayor abstracción: el civilizacional. Así, ya no hablaremos solamente del contexto social o cultural sino también del civilizacional que usualmente se invisibiliza en la academia occidental. Aquí se incorporan los distintos conocimientos, saberes y sabidurías gestados en otras civilizaciones en condiciones de igualdad, sin privilegios epistémicos y teniendo como eje central el respeto sumo a la naturaleza y a la vida. De esta manera, el conocimiento adquiere también el carácter de "sagrado" al quedar vinculado y en armonía con el cosmos (Lara, 2018, p.414).

\section{El contexto de todos los contextos: El respeto sagrado a la vida}

La proyección que le da esta propuesta al contexto no es en un sentido laico como correspondería a occidente hacerlo desde su antropocentrismo, aquí lo ampliamos al respeto sagrado a la vida. En esta sacralidad está considerada toda la humanidad y toda la vida del planeta en su magnanimidad y excelsitud. Así, el caracol, la guacamaya, el árbol, la cañada, el murciélago, el viento y cada persona constituyen un nudo más en la maya cósmica (Lara, 2018, p.424). En suma, esta propuesta se encamina a la descolonización del pensamiento que dé lugar a la creación de una nueva civilización no imperial que establezca, en condiciones de igualdad para todos, un puente entre los conocimientos, saberes y sabidurías de las distintas civilizaciones que tengan como eje central el sumo respeto que le debemos a la naturaleza. Esto adquiere especial relevancia ante los desequilibrios ecológicos del cambio climático que estamos presenciando en nuestros días. Considerando 
los planteamientos de Toledo (2015), estas alteraciones ambientales junto a la profunda desigualdad social son el reflejo de un problema mayor: una crisis de civilización. La decisión es nuestra, podemos seguir alimentando el proyecto de muerte de occidente, neoliberal, antropocéntrico, depredador y desacralizador del medio ambiente o retornar al proyecto de vida de los pueblos originarios, reestableciendo el contacto y el respeto sagrado a la vida y al cosmos.

\section{Referencias}

Armstrong, K. (2008). La historia de la Biblia. Barcelona: Debate.

Aymara, Org. (2010) No hay verbo Ser en Aymara. Recuperado de http://www.aymara.org/ lengua/2010/no-hay-verbo-ser-en-aymara/

Burton, M. (2000). Cristo y la creación de una cultura monocrática. En F. Herbert (Ed.) La genealogía del cristianismo: ¿Origen de occidente? México: CONACULTA

Carballo, F. (2012). Niklas Luhmann y la barbarie: Consideraciones sobre la inclusión y exclusión en la era planetaria. En M. Estrada, y R. Millán, (Ed.) La teoría de los sistemas de Niklas Luhmann a prueba. Horizontes de su aplicación en la investigación social en América Latina. México: El Colegio de México, Instituto de Investigaciones Sociales, UNAM.

De Bono, E. (1995). El pensamiento paralelo: De Sócrates a de Bono. España: Paidós.

De Sousa, B. (2011). Epistemologías del sur. Utopía y praxis latinoamericana. Revista internacional de filosofía Iberoamericana y teoría social, 16 (54), 17-39.

Deschner, k. (1986). Historia criminal del cristianismo. (Vol. 1). Barcelona: Martínez Roca.

Dussel, E. (1980). El ateísmo de los profetas y de Marx. Filosofía ética latinoamericana V: Arqueológica latinoamericana. Una filosofía de la religión antifetichista. Bogotá: Universidad Santo Tomás. Centro de enseñanza descolonizada

Dussel, E. (1994). 1492: El encubrimiento del otro: Hacia el origen del mito de la modernidad. La Paz: Plural Editores UMSA, Facultad de humanidades y ciencias de la educación.

Fernández, P. (2000). Hegel y el judaísmo. España: Riopiedras.

Grosfoguel, R. (2013). Racismo/sexismo epistémico, universidades occidentalizadas y los cuatro genocidios/epistemicidios del largo siglo XVI. Tabula Rasa. Colombia, 19, 31-58.

Hegel, G. (1976). Ciencia de la lógica. Argentina: Solar Ediciones.

Herrero, F. (2015). La interpretación hegeliana del judaísmo. En J. Caballero, y F. Herrero, (Eds.), Las horas de la filosofía. Homenaje al profesor Ildefonso Murillo (pp.55-66). Madrid: Diálogo filosófico.

Krishna, D. (1986). La filosofía comparada: Lo que es y lo que debería ser. Revista Diógenes, UNAM, 136, 57-67

Lara, J. (2018). Introducción a la meta epistemología de contextos. Un nuevo paradigma en las ciencias sociales y del hombre. En Prensa.

Navajas, S. (2015). Filósofos contra judíos. Recuperado de: elmedio.io/filósofos-contra-judios/ 
Reyes, M. (1998). Ilustraciones y judaísmo. En: M. Beltrán, JM. Mardones, M. Reyes (Eds), Judaísmo y límites de la modernidad. Barcelona: Riopiedras

Robles, F. y Arnold, M. (2001). El lugar del sujeto en la sociedad ¿Es posible una sociología reflexiva? Revista Metapolítica, 20, 68-89.

Serna, J. (2011). Las apuestas perdidas de occidente: Universales, inmortalidad y culto al presente. Barcelona: Anthropos.

Sperling, D. (1995). Genealogía del odio. Sobre el judaísmo en occidente. Argentina: Emecé Editores.

Taylor, A. y Hardman, M. (2004). War, language and gender, What new can be said? Framing the issues. Women and language, 27 (2), 3-19

Toledo, V. (2015). Ecocidio en México. La batalla final es por la vida. México: Grijalbo 